\title{
Mechanical and Tribological Properties of Carbon Thin Film with Tungsten Interlayer Prepared by Ion Beam Assisted Deposition
}

\author{
Petr Vlcak, ${ }^{1}$ Frantisek Cerny, ${ }^{1}$ Zdenek Tolde, ${ }^{1}$ Josef Sepitka, ${ }^{1}$ \\ Ivan Gregora, ${ }^{2}$ and Stanislav Danis ${ }^{3}$ \\ ${ }^{1}$ Faculty of Mechanical Engineering, Czech Technical University in Prague, Technicka 4, 16607 Prague 6, Czech Republic \\ ${ }^{2}$ Institute of Physics, AS CR, Na Slovance 2, 18221 Prague 8, Czech Republic \\ ${ }^{3}$ Faculty of Mathematics and Physics, Charles University in Prague, Ke Karlovu 5, 12116 Prague 2, Czech Republic \\ Correspondence should be addressed to Petr Vlcak; petr.vlcak@fs.cvut.cz and Frantisek Cerny; frantisek.cerny@fs.cvut.cz
}

Received 20 December 2012; Accepted 22 February 2013

Academic Editor: Maurizio Ferrari

Copyright (C) 2013 Petr Vlcak et al. This is an open access article distributed under the Creative Commons Attribution License, which permits unrestricted use, distribution, and reproduction in any medium, provided the original work is properly cited.

Mechanical and tribological properties of the thin carbon film with tungsten interlayer were investigated. The carbon film $(130 \mathrm{~nm})$ and the tungsten interlayer $(20 \mathrm{~nm})$ were prepared by ion beam assisted deposition (IBAD) method. Both layers were electron beam evaporated and were simultaneously irradiated by the beam of argon (Ar) or nitrogen $(\mathrm{N})$ ions with energy of $700 \mathrm{eV}$. Mechanical properties of the thin carbon film with tungsten interlayer were investigated by the nanoindentation method. Concerning tribological properties the coefficient of friction was investigated by means of pin on disc tribometer. Phase composition was investigated by X-ray diffraction method (XRD), and bonding characterization of carbon thin film was characterized by Raman spectroscopy.

\section{Introduction}

This paper deals with mechanical and tribological properties of the thin carbon film on Ti6Al4V alloy. Mechanical properties, that is, indentation hardness and reduced elastic modulus, were investigated by nanoindentation method. Concerning the tribological properties, the coefficient of friction was investigated by means of pin on disc tribometer. The titanium alloy Ti6Al4V is used, for example, in aerospace industry and automotive industry and biomedicine. The alloy has poor tribological properties [1]; hence different surface modifications are applied. One of these surface modifications is deposition of sliding carbon layer (known as diamond-like carbon (DLC)). These layers are prepared by way of different methods, for example, plasma enhanced chemical vapor deposition (PECVD), filtered cathode vacuum arc (FCVA), or ion beam assisted deposition (IBAD) [2-4]. Properties of carbon layers depend on the type of bonding between the atoms, chemical composition, and deposition conditions [5]. In this paper, the carbon thin films were prepared by IBAD method. This deposition method combines evaporation of the layer and ion bombardment. The advantage of this method is precise control of the deposition process. Controlled ion bombardment enables mixing of the atoms on the interface coating/substrate. This phenomenon can contribute to the improvement of coating adhesion [6].

\section{Experiment Details}

The substrates were made of titanium alloy Ti6Al4V in the form of discs with diameter $20 \mathrm{~mm}$ and height $6 \mathrm{~mm}$. Roughness of the substrate $\mathrm{Ra}$ was after polishing lower than $0.02 \mu \mathrm{m}$. The polishing of the substrates was followed by cleaning in organic solvents with the ultrasound. Next step was cleaning in the argon ion beam. Deposition of tungsten interlayer and carbon thin film was performed by electron beam evaporation of tungsten and carbon tablet. The thickness of the tungsten interlayer was $20 \mathrm{~nm}$ and the 


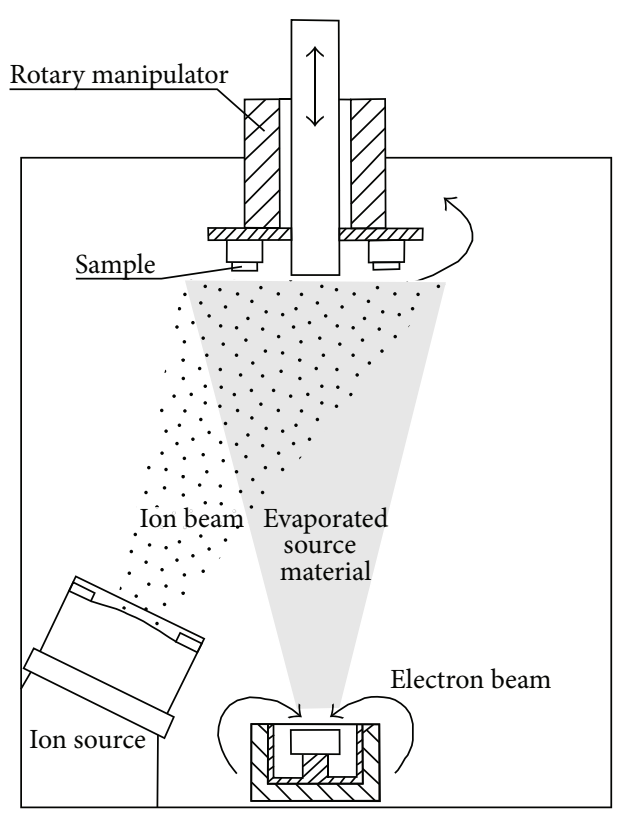

FIGURE 1: Schematic representation of IBAD deposition method apparatus.

thickness of the carbon film was $130 \mathrm{~nm}$. During evaporation the tungsten interlayer and carbon thin film were irradiated by a small fluence of argon or nitrogen ions with energy $700 \mathrm{eV}$ for intermixing atoms at interface between nanolayer and substrate for improvement of adhesion and for carbon layer modification.

The electron beam evaporation of layers and the irradiation by argon or nitrogen ions were carried out in the apparatus for IBAD method whose schematic representation is in Figure 1.

\section{Results and Discussion}

Mechanical properties, that is, indentation hardness and reduced elastic modulus, were investigated by nanoindenter. This method was used for the measurement of the depth profile of mechanical properties. Maximum indentation load was $5000 \mu \mathrm{N}$. 12 indents in a matrix $3 \times 4$ were performed. The distance between the indents was $5 \mu \mathrm{m}$. The depth profiles of the indentation hardness and reduced elastic modulus are plotted in Figures 2 and 3. Maximum value of indentation hardness was $12 \mathrm{GPa}$ in depth of $8 \mathrm{~nm}$ and elastic modulus was $143 \mathrm{GPa}$ in depth of $7 \mathrm{~nm}$ for the sample with the carbon thin film bombarded by Ar ions. The hardness was $10.5 \mathrm{GPa}$ in depth of 13-18 nm and elastic modulus was $122 \mathrm{GPa}$ in depth of $7-8 \mathrm{~nm}$ for the sample with carbon thin film bombarded by $\mathrm{N}$ ions. The thin carbon film with tungsten interlayer significantly increased the surface hardness in comparison with uncoated Ti6Al4V alloy (about 5.3 GPa-see Figure 2).

Tribological properties, that is, coefficient of friction, were investigated on pin on disc tribometer with $100 \mathrm{Cr} 6$ steel ball with diameter $6 \mathrm{~mm}$. The normal load was $2 \mathrm{~N}$, the radius of rotation was $4 \mathrm{~mm}$, and the velocity was $6 \mathrm{~cm} \cdot \mathrm{s}^{-1}$. Tests proceeded at laboratory ambient temperature without

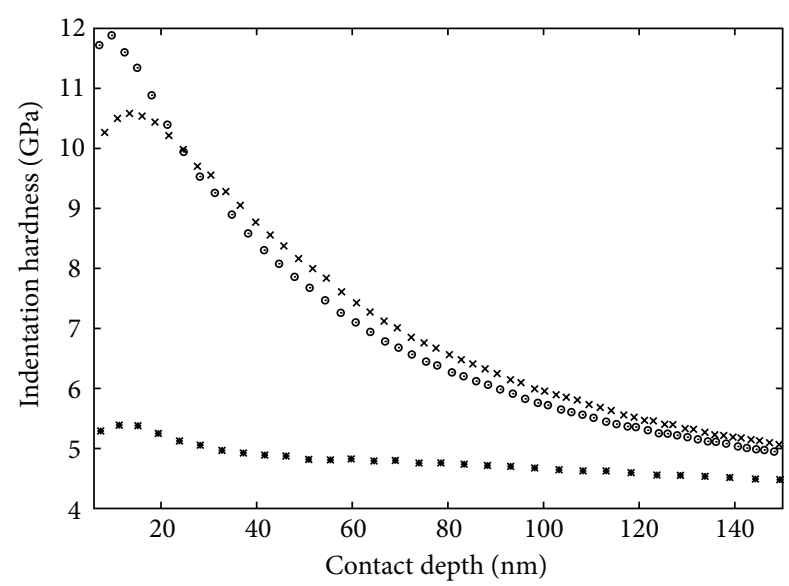

$\odot \mathrm{C}+\mathrm{W}+$ Ar coating
$\times \mathrm{C}+\mathrm{W}+\mathrm{N}$ coating
$*$ Substrate

Figure 2: Depth profile of indentation hardness.

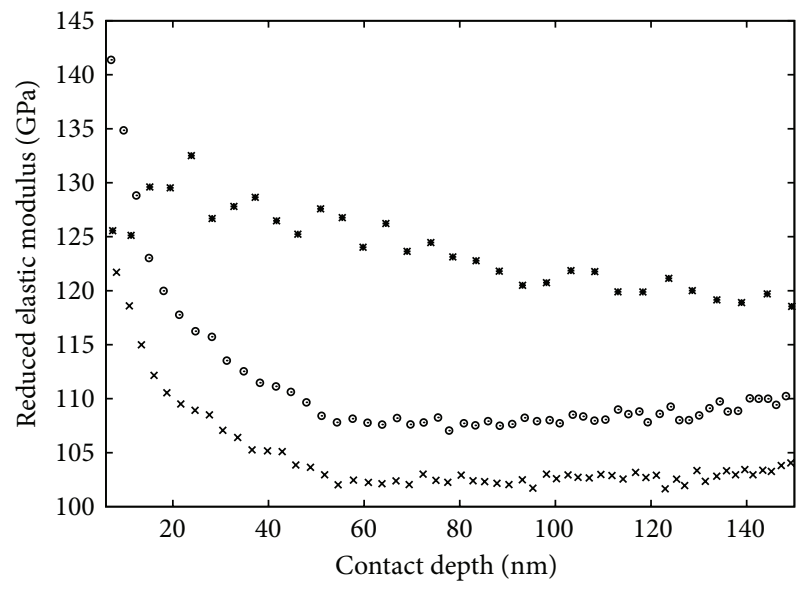

- $\mathrm{C}+\mathrm{W}+$ Ar coating

$\times \mathrm{C}+\mathrm{W}+\mathrm{N}$ coating

* Substrate

FIGURE 3: Depth profile of reduced elastic modulus.

lubrication. The results of tribological tests are shown in Figure 4.

Coefficient of friction of carbon thin film bombarded by Ar ions decreased to 0.08 . Coefficient of friction of carbon thin film bombarded by $\mathrm{N}$ ions was lower than 0.11 . Both carbon coatings had very low coefficient of friction of about 0.1 in comparison with uncoated Ti6Al4V alloy (about $0.6-$ see also Figure 4).

The mechanical and tribological tests of carbon thin films were completed by their bonding characterization by Raman spectroscopy. Resulted Raman spectra of both carbon thin films are depicted in Figure 5.

The Raman spectra were investigated by Raman microscope. Raman spectra were excited with the $514.5 \mathrm{~nm}$ line of an Ar laser focused to area of about $3 \mu \mathrm{m}^{2}$ at a power around 


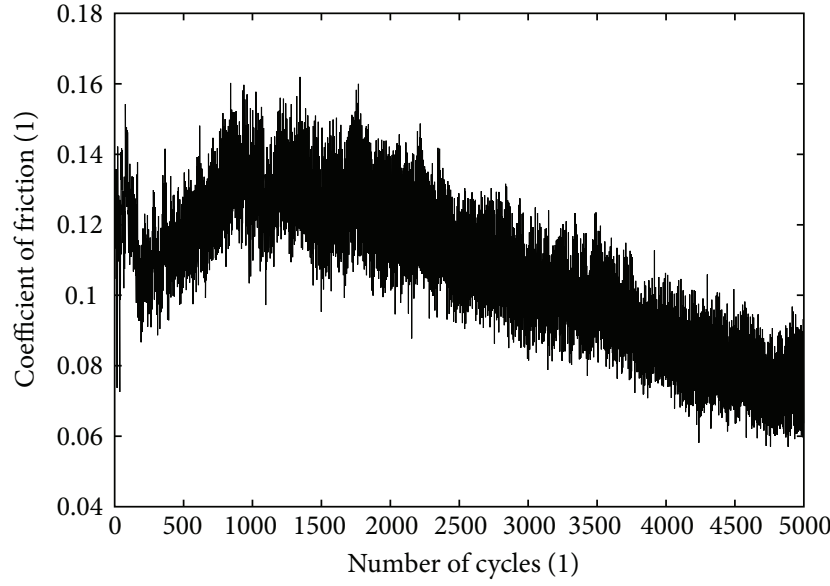

(a)

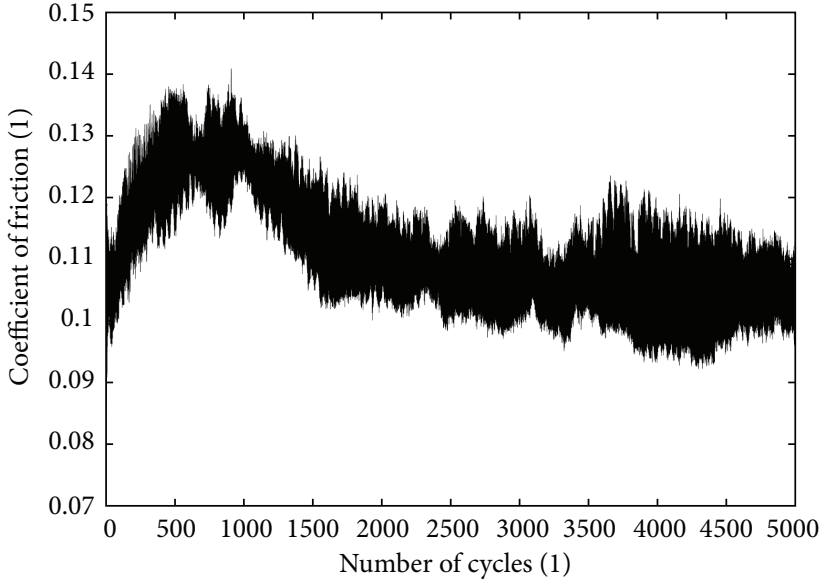

(b)

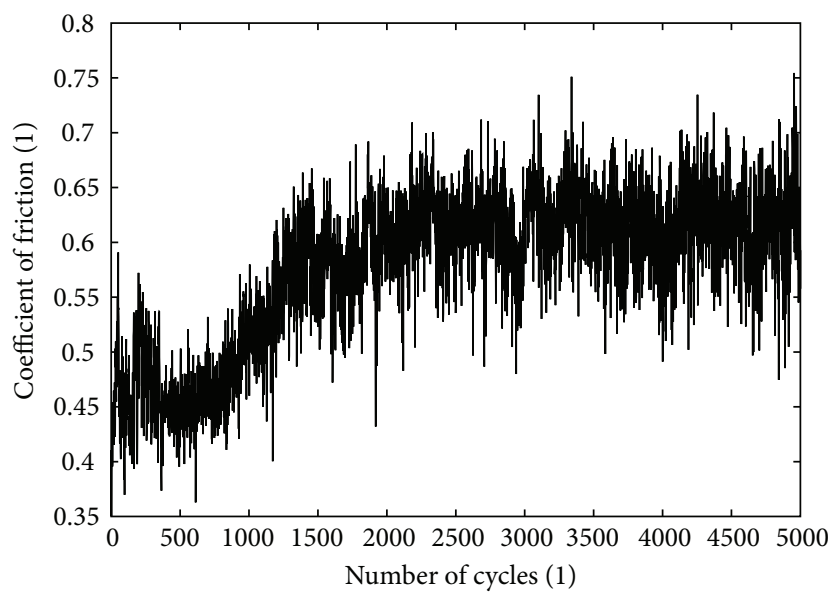

(c)

FIGURE 4: Results of tribological tests of carbon thin film with tungsten interlayer bombarded by Ar ions (a), N ions (b), and uncoated Ti6Al4V alloy (c).

$0.2 \mathrm{~mW}$. The spectral slit width was $1.5 \mathrm{~cm}^{-1}$. The spectra have the DLC (diamond-like carbon) character; that is, they are composed of the D (disorder) and G (graphitic) peaks. A little significant $D$ peak is at about $1350 \mathrm{~cm}^{-1}$ and significant $\mathrm{G}$ peak is at about $1535 \mathrm{~cm}^{-1}$. It indicates predominantly graphitic character of the carbon films.

Phase composition was investigated by means of $\mathrm{X}$ ray diffraction method (XRD). The phases of $\mathrm{TiC}$ and $\mathrm{TiN}$ were observed in the both types of the samples. The peaks characterizing TiN are less intensive for the samples with the carbon thin film bombarded by Ar ions. The diffraction spectra of both types of the samples are in Figure 6.

\section{Conclusions}

The properties of thin carbon film with tungsten interlayer prepared by ion beam assisted deposition method on Ti6Al4V alloy were studied. Two types of a coating varying in a type of bombarding ions (Ar or $\mathrm{N}$ ) were created.

The thin carbon film with tungsten interlayer increased significantly the surface hardness in comparison with uncoated Ti6Al4V alloy. The samples with the carbon thin film bombarded by Ar ions exhibited higher indentation hardness in comparison to the samples with the carbon thin film bombarded by $\mathrm{N}$ ions.

Carbon thin films had significantly decreased coefficient of friction in comparison with uncoated alloy. Coefficient of friction of the sample with carbon thin film bombarded by $\mathrm{Ar}$ ions was reduced to 0.08 .

The mechanical and tribological tests of carbon thin films were completed by their bonding characterization by Raman spectroscopy and phase composition by X-ray diffraction method. The Raman spectra of both types of the samples have the DLC character with small significant D peak which indicates graphitic character of the carbon films. The diffraction spectra imply the TiC and TiN phases in both types of the samples. The peaks characterizing TiN are less intensive for the samples with the carbon thin film bombarded by Ar ions.

\section{Conflict of Interests}

The authors do not have any conflict of interests. 


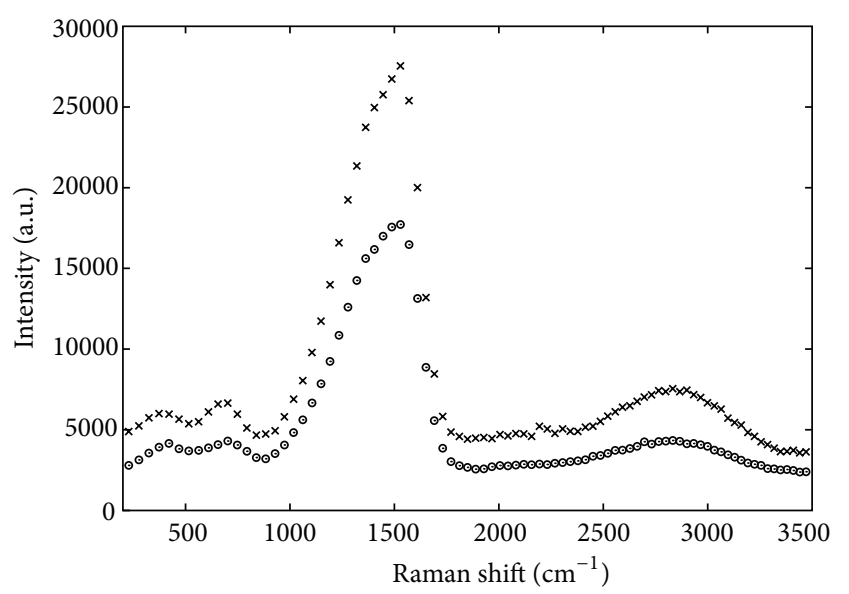

$\times \mathrm{C}+\mathrm{W}+\mathrm{N}$ coating

$\circ \mathrm{C}+\mathrm{W}+$ Ar coating

Figure 5: Raman spectra of carbon thin films.

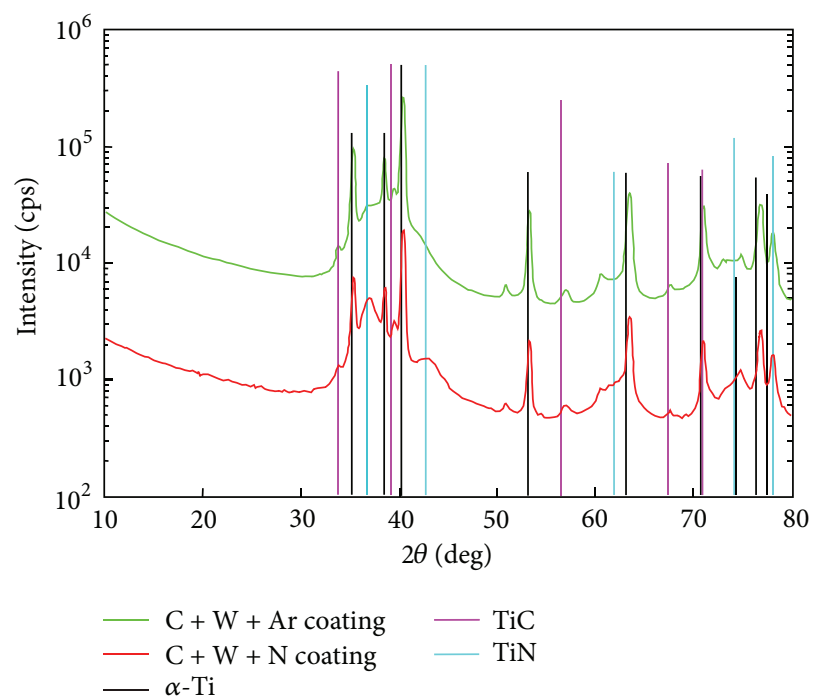

Figure 6: Diffraction spectra of carbon thin films with tungsten interlayer bombarded by Ar or $\mathrm{N}$ ions.

\section{Acknowledgment}

This research has been supported by the Ministry of Education of Czech Republic Project SGS10/245/OHK2/3T/12.

\section{References}

[1] M. Geetha, A. K. Singh, R. Asokamani, and A. K. Gogia, "Ti based biomaterials, the ultimate choice for orthopaedic implants-a review," Progress in Materials Science, vol. 54, no. 3, pp. 397-425.

[2] L. Q. Gou, X. L. Shi, X. M. Zhao, Y. Bai, and L. J. Qiao, "Composite diamond-DLC coated nanoprobe tips for wear resistance and adhesion reduction," Surface and Coatings Technology, vol. 206, no. 19-20, pp. 4099-4105, 2012.
[3] G. G. Wang, H. Y. Zhang, W. Y. Li et al., "The preparation and evaluation of graded multilayer ta-C films deposited by FCVA method," Applied Surface Science, vol. 257, no. 11, pp. 5064-5069, 2011.

[4] S. Wei, T. Shao, and J. Xu, "Effect of bombarding energy of $\mathrm{N}$ ions on composition, hardness and surface free energy of carbon nitride films," Surface and Coatings Technology, vol. 206, no. 19-20, pp. 3944-3948, 2012.

[5] M. C. Salvadori, F. S. Teixeira, W. W. R. Araújo, L. G. Sgubin, and I. G. Brown, "Interface tailoring for adhesion enhancement of diamond-like carbon thin films," Diamond \& Related Materials, vol. 25, pp. 8-12, 2012.

[6] Y. Funada, K. Awazu, H. Yasui, and T. Sugita, "Adhesion strength of DLC films on glass with mixing layer prepared by IBAD," Surface and Coatings Technology, vol. 128-129, no. 1, pp. 308-312, 2000. 

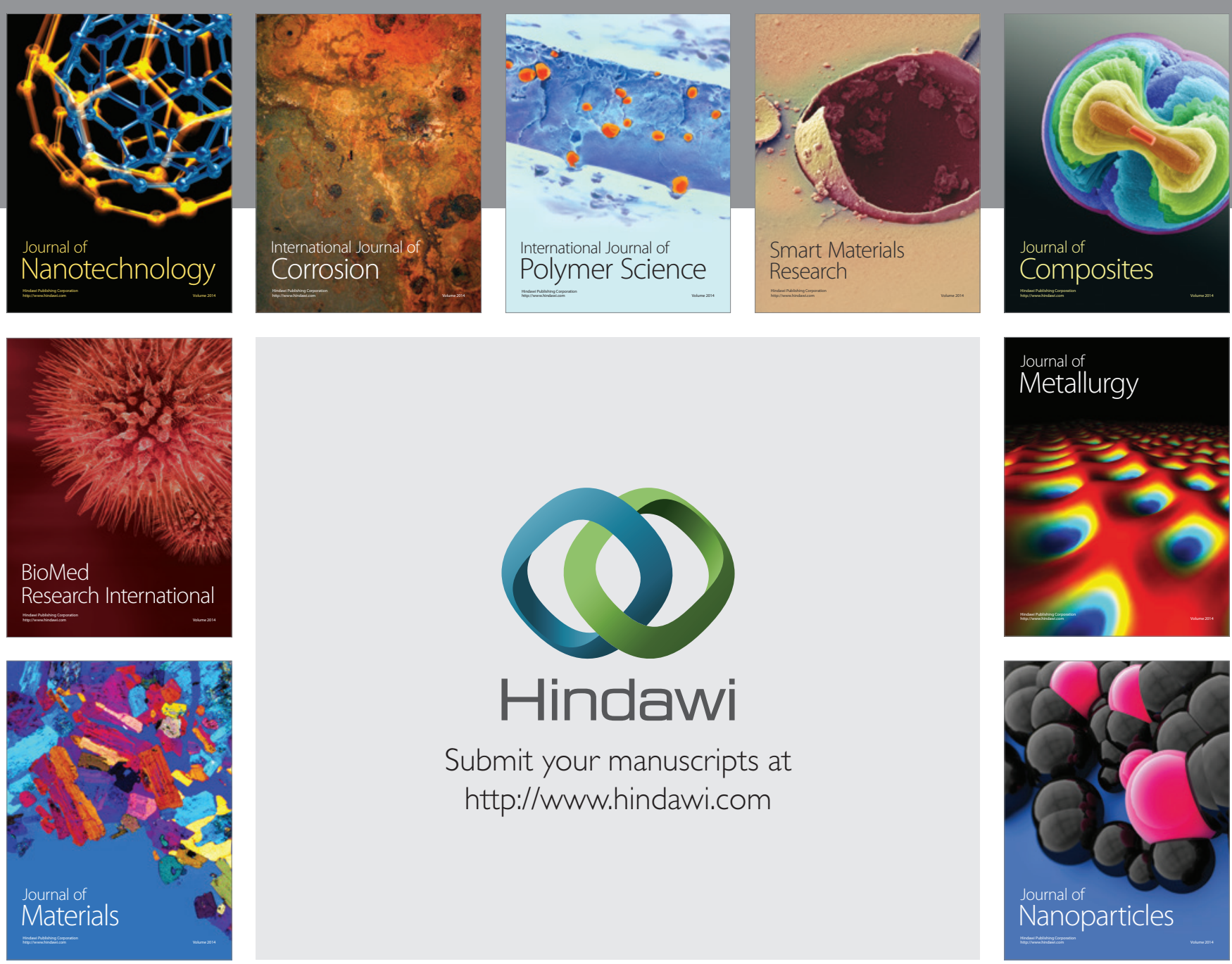

Submit your manuscripts at http://www.hindawi.com
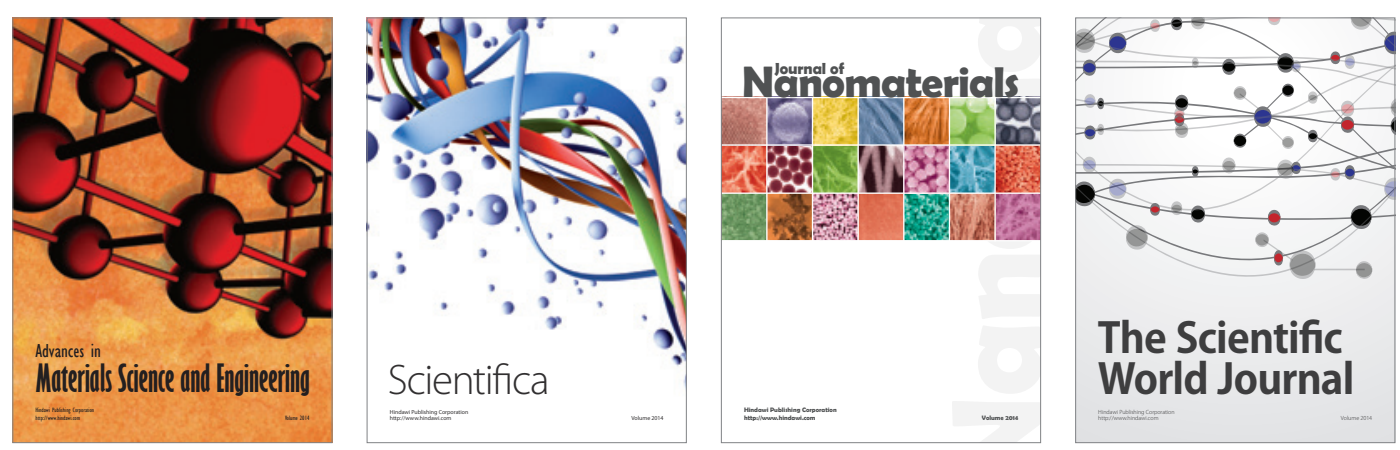

\section{The Scientific World Journal}
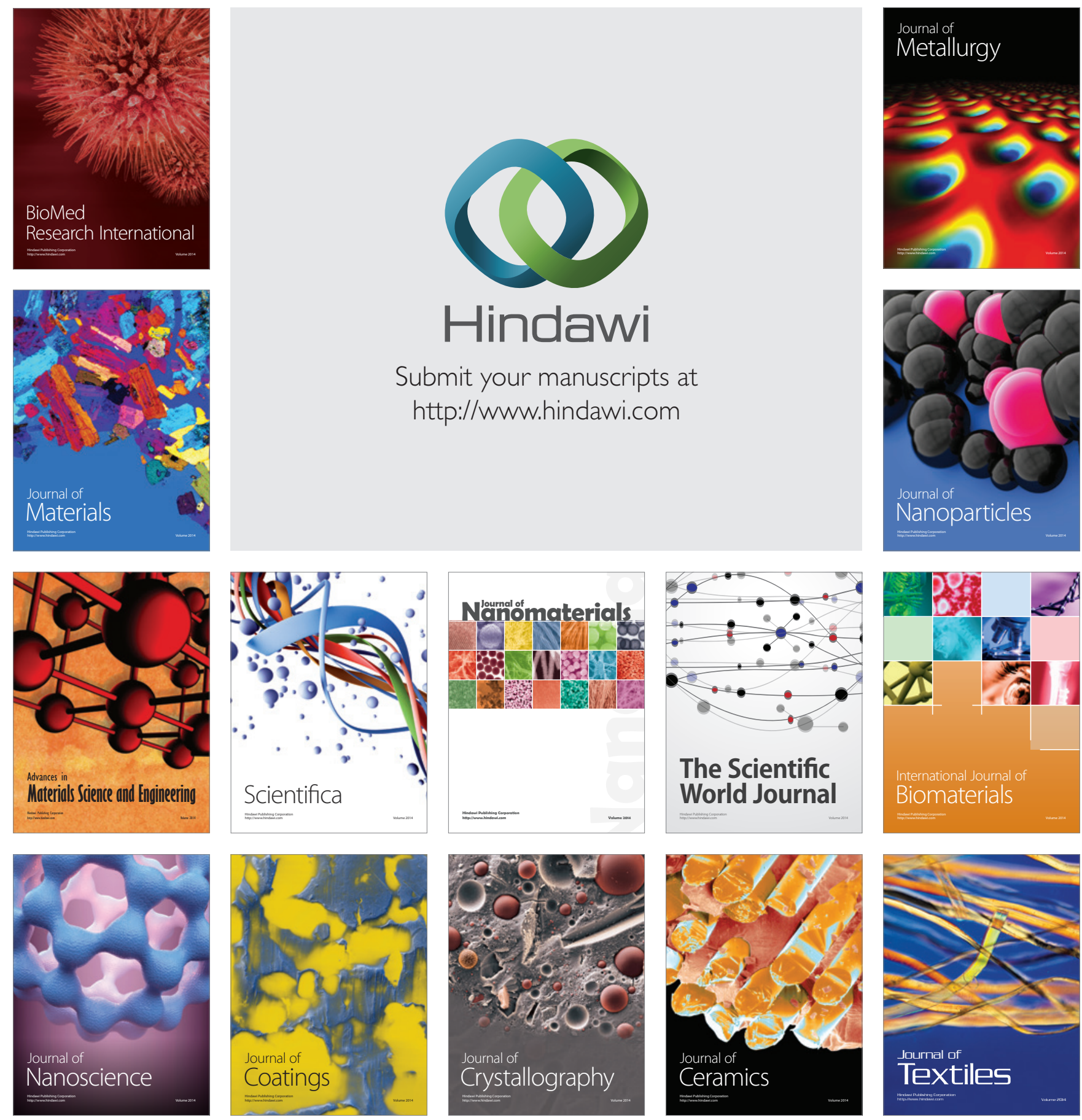